\title{
Study On the Thickness of Biological Soil Crusts in Different Desertification Ecosystem Areas
}

Bai $\mathrm{Li}^{1,2, \mathrm{a}^{*}}$, Wei Qin ${ }^{1,2, \mathrm{~b}}$, Changqing Zuo ${ }^{1,2, \mathrm{c}}$, Zhe Yin ${ }^{1,2, \mathrm{~d}}$, Nan Yan ${ }^{1,2, \mathrm{e}}$, Qiankun Guo ${ }^{1,2, f}$, Zhijie Shan ${ }^{1,2, g}$, Zhaoyan Wang ${ }^{1,2, h}$

${ }^{1}$ State Key Laboratory of Simulation and Regulation of Water Cycle in River Basin, China Institute of Water Resources and Hydropower Research, Beijing 100048, China;

${ }^{2}$ Research Center on Soil and Water Conservation of the Ministry of Water Resources, China Institute of Water Resources and Hydropower Research, Beijing 100048, China;

albyn1986@hotmail.com, 'binwei_office@sina.com, 'czuochq@sina.com, dyinzhe-2002@163.com,

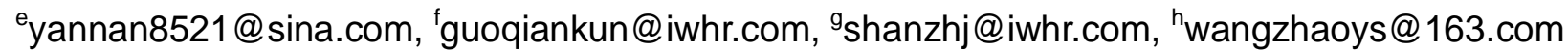

Keywords: Biological soil crusts; The thickness of biological soil crusts; Desertification ecosystem areas.

Abstract. Biological soil crusts serve as a vanguard for improving the ecological environment in arid, semi-arid desertification areas. It is a good indicator of the improvement status which the local ecological environment is undertaking. This study was completed in Yanchi in Ningxia province and Dengkou in the Inner Mongolia Autonomous Region from 2010 to 2011. Through field investigation to study on the thickness of biological soil crusts, find characteristics of biological soil crusts thickness stage. The results show that: Biological soil crusts thickness decreases with increasing distance roots. The biological soil crusts thickness distribution is associated with the crown of plants in different directions. Comparing two kinds of desertification ecosystem, the thickness of the biological soil crust in Mu Us Desert were thicker than that in Ulan Buh Desert.

\section{Introduction}

In arid, semi-arid desertification areas, biological soil crusts are widely used in the area of low productivity, and it is a kind of soil type which is composed of biological components in the surface soil layer ${ }^{[1,2]}$. According to the development degree of biological soil crust and its composition, it can be divided into algal crusts, lichen crusts, algal-lichen crusts, cyanobacteria- algae crusts, cyanobacteria-lichen crusts, lichen-moss crusts, and so on ${ }^{[3]}$. Biological soil crusts thickness is the thickness when algal crusts can be completely peeling off when soil is dry and an external force applied $^{[4]}$. A marked sign of the degradation of vegetation in the sand land is the fixed degree of the surface. In general, the vegetation restoration is better, and the degree of immobilization of the sand is higher. Reflecting the degree of surface fixation is a direct indicator of the thickness of the surface crusts ${ }^{[5]}$. The crust thickness is thin, can be divided into two parts, the upper is crust cortex, the lower is soil compaction layer ${ }^{[6-9]}$. With the increase of sand fixing ages, gradual development of biological soil crusts on the sand, generally will be the developmental stages divided into crisp powder crust, thin and crispy crust, tighter flaky crust and tight flake, block crusts ${ }^{[10]}$. The longer the time, the longer the vegetation growth, the more the biological crusts, the greater the coverage, the greater the thickness, the thickness of the crust is between 0.3 and $1.5 \mathrm{~cm}^{[11]}$. With the increase of vegetation coverage, the thickness of biological soil crusts under the plant is greater. The large thickness of biological soil crusts is unfavorable to the moisture of the soil, the vegetation can't get enough moisture, so that it can affect the continuous recovery of vegetation, and it is also one of the 
reasons that lead to the decline of the old fixed dunes ${ }^{[12]}$. Based on the research of biological soil crusts thickness by the domestic and foreign experts and scholars. Study on distribution characteristics of biological soil crusts thickness in Mu Us Desert and Ulan Buh Desert. In order to find out the variation of the spatial distribution of biological soil crusts thickness. Biological soil crusts better recovery for the ecosystem area and the ecological environment construction services.

\section{Materials and methods}

\section{Site location and characteristics}

The $1 \#$ study area is located at Yanchi, Ningxia province $\left(37^{\circ} 4^{\prime}-38^{\circ} 10^{\prime} \mathrm{N}, 106^{\circ} 30^{\prime}-107^{\circ} 41^{\prime} \mathrm{E}\right)$ covering an area of $7130 \mathrm{~km}^{2}$ (Figure 1). The north region of Yanchi County is connected with $\mathrm{Mu}$ Us Desert. The landform is complex with undulating terrain. Its land type consists of mainly beach, flat ground, gentle slope, hilly and dune ${ }^{[13]}$. The climate of Yanchi County is in a transition zone from semi-arid to arid areas, which is a typical temperate continental climate. The average annual rainfall is $280 \mathrm{~mm}$ and the annual evaporation is $2100 \mathrm{~mm}^{[14]}$. The perennial dominant wind direction is northwest. Vegetation flora in Yanchi County is in a transition zone between Eurasian steppe, Central Asia sub-region and central China loess plateau. Vegetation in the county is short, scarce with no natural forest. Perennial wild herbs are widely distributed, along with semi-shrub and shrubs. The vegetation can be categorized into five types: grasslands, thickets, meadows, sand vegetation and desert vegetation. Shrubs, grasslands and sand vegetation are greater in number and also more widespread. Sandy vegetation mainly consists of bitter beans formations, bovine heart Puzih formations, Artemisia formations and sphaerocephala formations, along with white thorn formations, Splendens formations and Kalidium formations. Growth of biological crusts in the region is closely related to the rainfall, most of them are initial sand crust and biological crusts with fungi. The soil type mainly consists of sierozem, aeolian sandy soil, black loam and saline soil, of which sierozemand aeoilian sandy soil accounted for $75 \%$ of the total amount.

The 2\# study area is located at Dengkou, Inner Mongolia Autonomous Region $\left(40^{\circ} 9^{\prime}-40^{\circ} 57^{\prime} \mathrm{N}\right.$,

$106^{\circ} 9^{\prime}-107^{\circ} 10^{\prime} \mathrm{E}$ ) covering an area of $4167 \mathrm{~km}^{2}$ (Figure 1). The south region of Dengkou County is connected with Ulan Buh Desert. The landform is also complex with undulating terrain. The terrain is dominated by sand dunes, which accounts for more than $60 \%$ of the total area. The climate of Dengkou County is a typical continental monsoon climate. The average annual rainfall is $144 \mathrm{~mm}$ and the annual evaporation is $2400 \mathrm{~mm}$. The perennial dominant wind direction is southwest. Vegetation flora in Dengkou County is desert vegetation. Vegetation in the county is short, scarce with a little of natural forest. Perennial wild herbs are widely distributed, along with semi-shrub and shrubs. The vegetation also can be categorized into six types: grasslands, thickets, meadows, sand vegetation, desert vegetation and desert trees. Shrubs and sand vegetation are greater in number and also more widespread. Desert tree is Haloxylon ammodensron Bunge. Shrubs include Tamarix chinensis, Artemisia ordosica, Nitraria tangutorum Bobr, Hedysarum scoparium and Hedysarum Mongolicum. Herbal include Cynanchum thesioides, Kalidium foliatum, Bassia dasyphylla and so on. Biological soil crust species in Dengkou County mainly include algal crusts, lichen crusts and moss crusts. The soil types in Dengkou County are gray desert soil, brown soil and aeolian sandy soil. There are 280 kinds of soil types and the overall performance is degraded. 


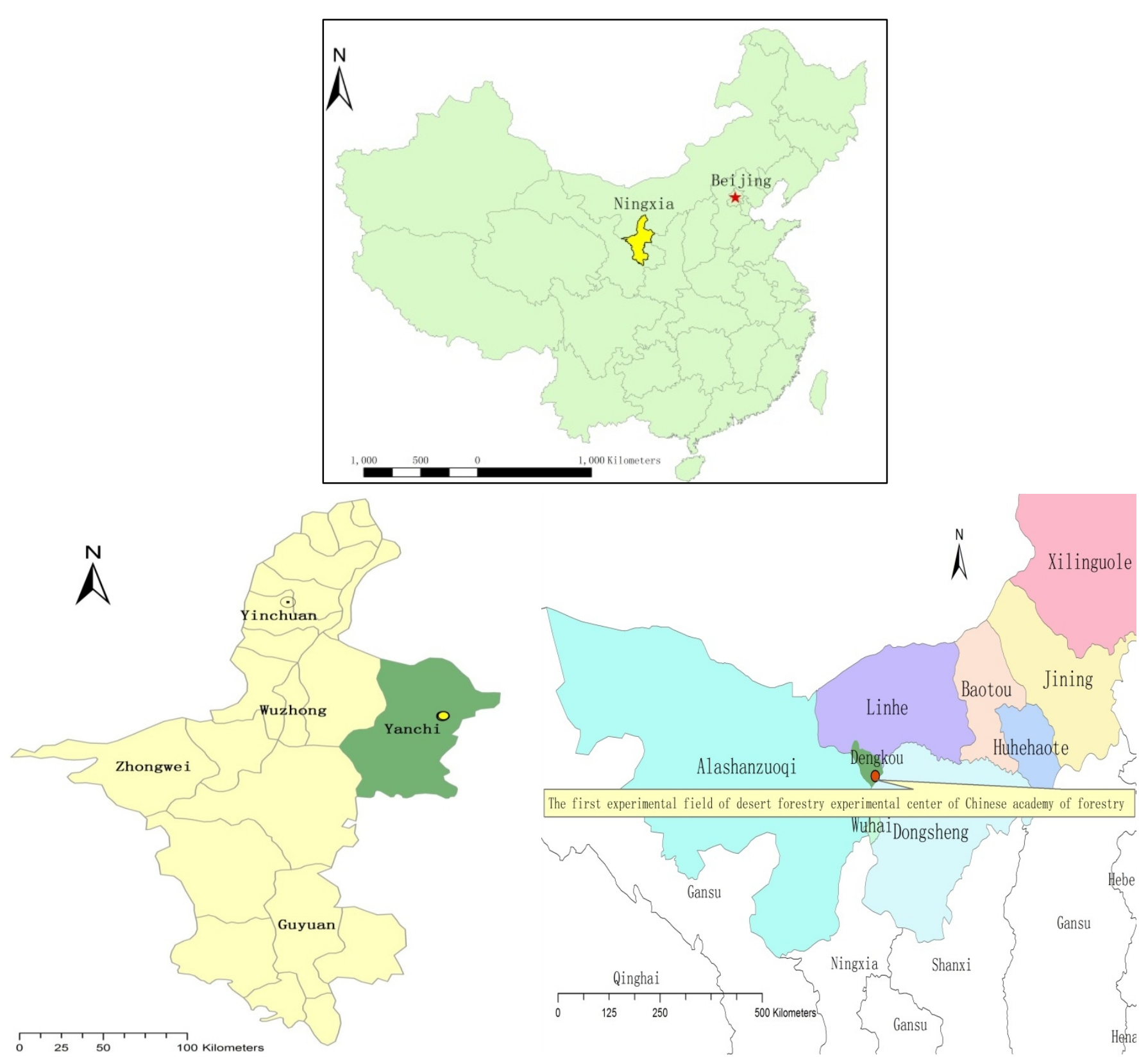

Fig.1 Yanchi and Dengkou County geography position maps and the samples locations map

\section{Research technique}

Method for measuring the thickness of biological soil crusts: Take a size of $2 \mathrm{~cm} \times 2 \mathrm{~cm}$ and $2 \mathrm{~cm}$ thick soil block verticality with soil knife in the sample plot. Shake loose sand lower than the biological soil crusts gently. Measure the thickness with vernier caliper. Measurement repeated 10 times.

Taking transect lines randomly in Mu Us desert. Typical sample Artemisia ordosica, Hedysarum Mongolicum, Hedysarum Scoparium with moss, lichen and algal crusts were selected (16 groups each), drawing 48 plots with a size of $4 \mathrm{~m} \times 4 \mathrm{~m}$. The location and altitude of the plots were recorded. 
Measure biological soil crust thickness, which is in different directions under the coverage of vegetation canopy. Measurement repeated 10 times.

Taking transect lines randomly in Ulan Buh desert. Typical sample Artemisia ordosica, Tamarix Chinensis with moss, lichen and algal crusts were selected (16 groups each), drawing 32 plots with a size of $4 \mathrm{~m} \times 4 \mathrm{~m}$. The location and altitude of the plots were recorded. Measure biological soil crust thickness, which is in different directions under the coverage of vegetation canopy. Measurement repeated 10 times.

\section{Data analysis}

The relationship between the thickness of biological soil crusts and the distance to the root of the vegetation was assessed by SPSS single factor correlation analysis. The figures were drawn using Origin 9.0 (OriginLab Inc., Northampton, MA, USA).

\section{Results}

\section{In Mu Us Desert}

Figure 2, 3 and 4 are indicated that distribution of three types biological soil crusts under the coverage of Artemisia ordosica, Hedysarum Mongolicum and Hedysarum Scoparium. The linear negative correlation between the thickness of the three types biological soil crusts and the distance of three types vegetation was found $(\mathrm{p}<0.01)$. The three types biological soil crusts all show that the bigger the distance, the smaller the thickness.

Under the coverage of three types vegetation, the maximum thickness of algae crusts was found in root position, were $0.53 \mathrm{~cm}, 0.61 \mathrm{~cm}$ and $0.63 \mathrm{~cm}$ respectively. The maximum thickness of lichen, moss crusts also appeared in root position. The minimum value of algae, lichen and moss crusts was reached at $80 \mathrm{~cm}$ from the root. When the velocity of three types biological soil crusts under the vegetation coverage was decreased, the distance was increased. The result was indicated that from $0 \mathrm{~cm}$ to $80 \mathrm{~cm}$, the average thickness of three types biological soil crusts was $0.05 \mathrm{~cm}$ per $10 \mathrm{~cm}, 0.08 \mathrm{~cm}$ per $10 \mathrm{~cm}$, and $0.10 \mathrm{~cm}$ per $10 \mathrm{~cm}$, respectively. At the same location related to the Artemisia ordosica vegetation, the average thicknesses of the three types biological soil crusts are ordered by moss crusts $>$ lichen crusts $>$ algae crusts. At the same location related to the same vegetation, the average thicknesses of the same biological soil crusts are ordered by under Hedysarum Scoparium coverage>under Hedysarum Mongolicum coverage > under Artemisia ordosica coverage. The difference between the thickness of the three types biological soil crusts and the distance from the root of the vegetation was not significant $(p>0.05)$.

The thickness of the biological crust is negatively related to its coverage under the vegetation $\operatorname{cover}\left(\mathrm{R}^{2}=0.991, \mathrm{p}<0.01\right)^{[15]}$. It is different from "The more the biological crusts, the greater the coverage, the greater the thickness" by Y. Cui et al. and Gundlapally ,Garcia-Pichel ${ }^{[10,16]}$. In Mu Us desert, the thickness of the crust is increasing, causing the shallow stratification of the precipitation, so that the vegetation in the community can decrease the utilization rate of water, which can lead to the death of vegetation. With the death of vegetation, biological soil crusts lack of protective effect of upper canopy, understory niche has also been varying degrees of damage, biological soil crusts will also decline, resulting in biological soil crusts coverage has decreased, a lot of decline, or even disappear. 


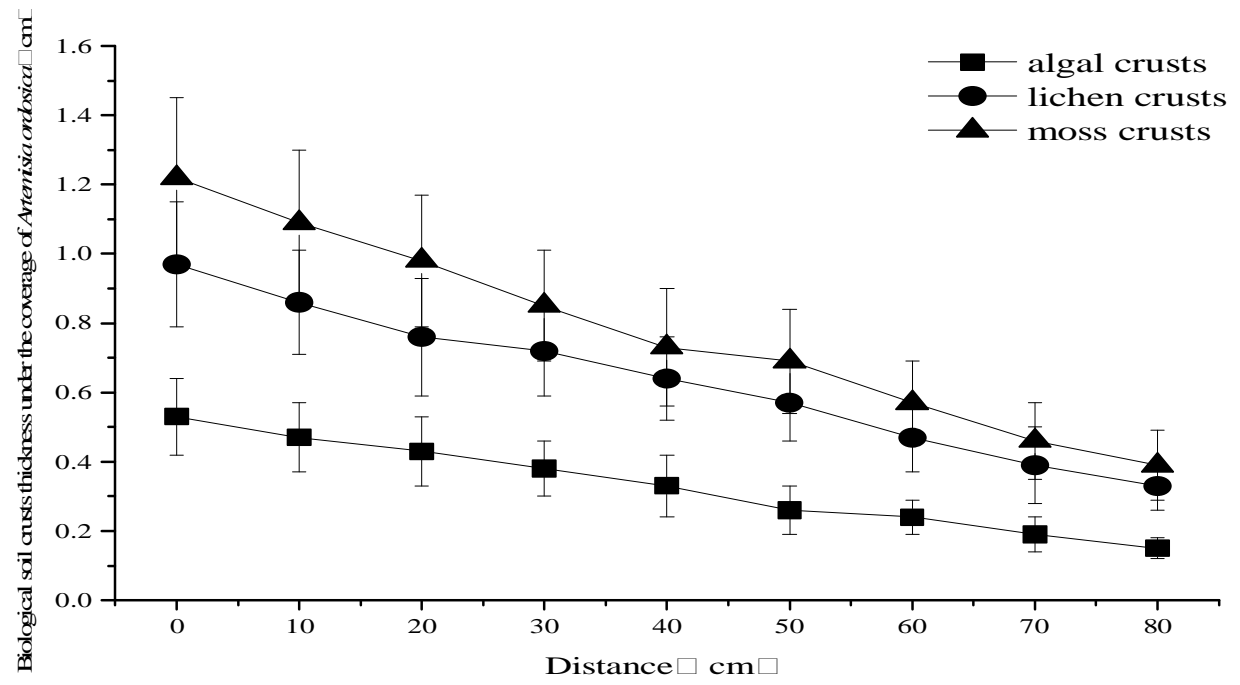

Fig.2 Biological soil crusts thickness under the coverage of Artemisia ordosica in Mu Us desert

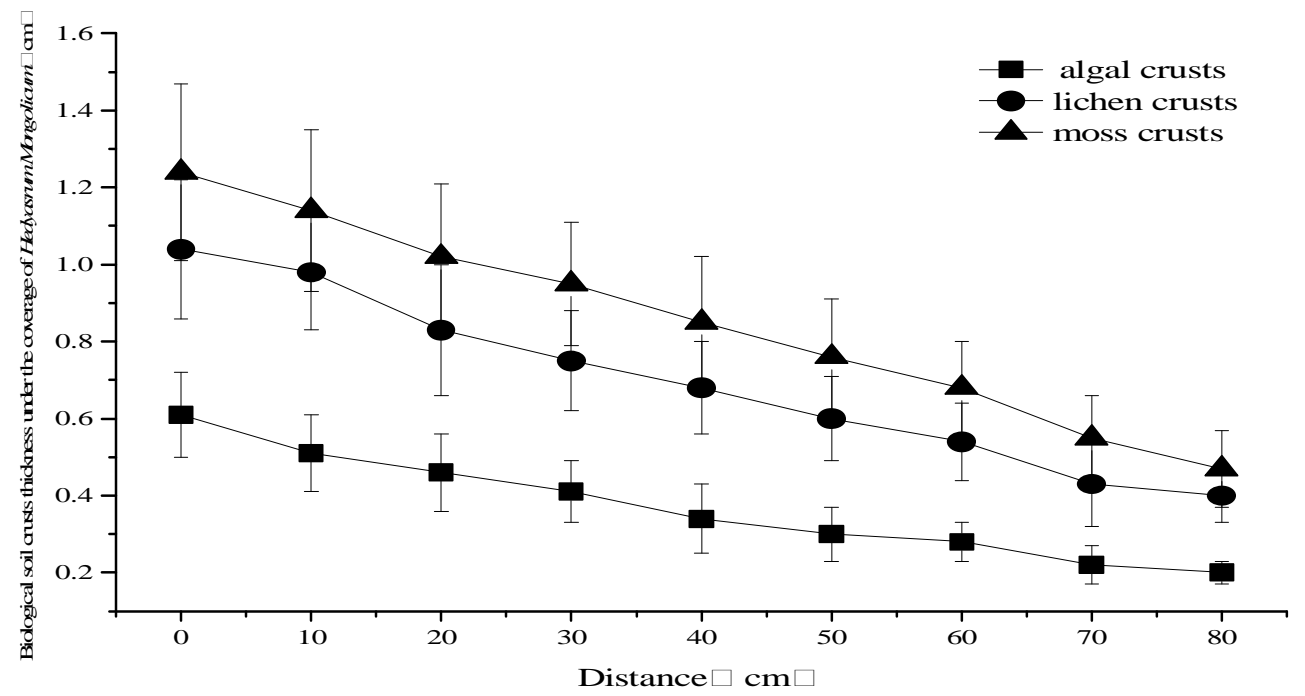

Fig.3 Biological soil crusts thickness under the coverage of Hedysarum Mongolicum in Mu Us desert

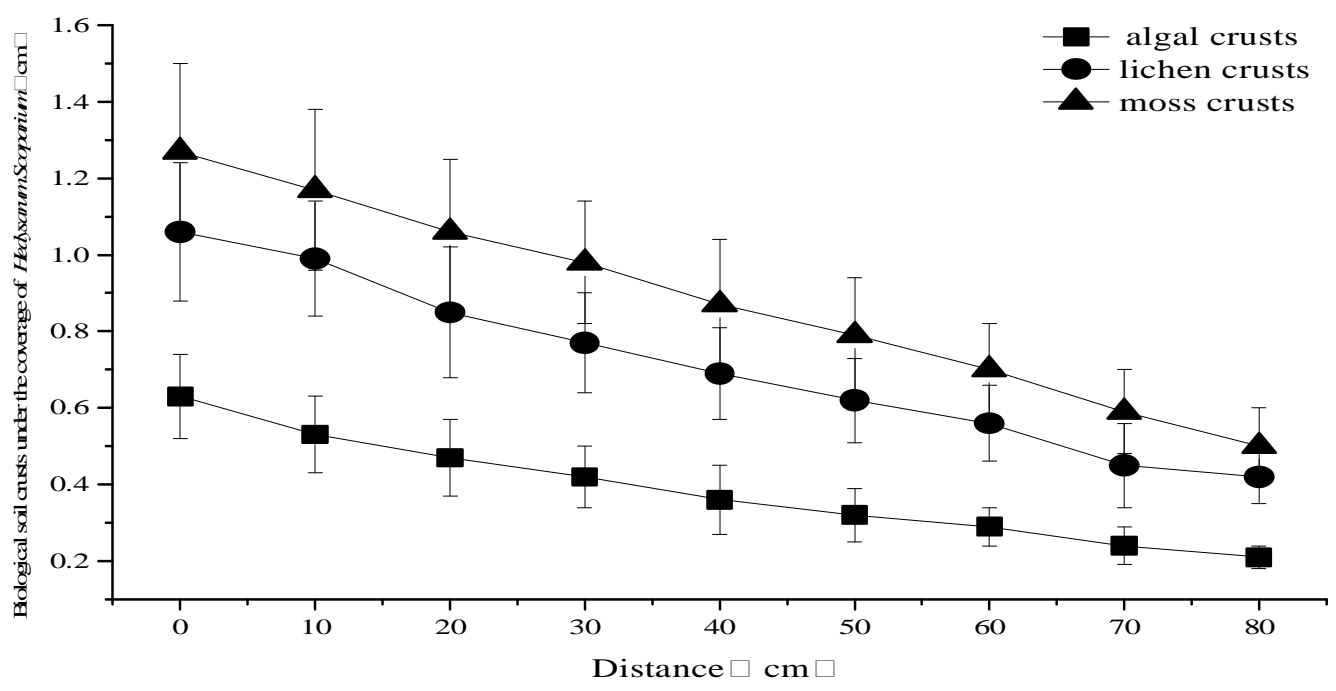

Fig.4 Biological soil crusts thickness under the coverage of Hedysarum Scoparium in Mu Us desert 


\section{In Ulan Buh Desert}

Figure 5 and 6 are indicated that distribution of three types biological soil crusts under the coverage of Artemisia ordosica and Tamarix Chinensis. The linear negative correlation between the thickness of algal, lichen, moss crusts and the distance of three types vegetation was found $(\mathrm{p}<0.01)$. The three types biological soil crusts all show that the bigger the distance, the smaller the thickness. Under the coverage of Artemisia ordosica, lichen and moss crusts thickness were significantly greater than algae crusts. The maximum of the algal crusts was in the root, is $0.47 \mathrm{~cm}$. The maximum of lichen and moss crusts appeared in the same position, respectively, 1.68 times and 1.94 times as the thickness of algal crusts. From $0 \mathrm{~cm}$ to $80 \mathrm{~cm}$, algal crusts thickness decreased by $0.04 \mathrm{~cm}$ per $10 \mathrm{~cm}$. Lichen and moss crusts thickness decreased by $0.07 \mathrm{~cm}$ per $10 \mathrm{~cm}$, the rate of decline was faster. Under the same vegetation cover, when the thickness of the three types biological soil crusts decreased, the distance from the root of the vegetation increased. The average thicknesses of the three types biological soil crusts under the different vegetation cover and the same distance from the root of the vegetation, which are ordered by moss crusts> lichen crusts > algae crusts.

The thickness of biological soil crust and its coverage are positive correlation in Ulan Buh desert, which were different results from Mu Us desert. This is mainly related to the site conditions, the succession of vegetation and the types of biological components of biological soil crusts. In Ulan Buh desert, Tamarix Chinensis as a succession of community, its crown tall, understory nutrient and water conditions are good, covered with a large number of litter layer, biological soil crusts in the place had been protected by other species of vegetation in other areas. The increase of the thickness of the biological soil crusts, also makes the area of the phenomenon of shallow layer of rainfall, shallow root of small shrubs and herbs have been better growth, water cannot penetrate into the depths of the soil, resulting in the decline of Artemisia ordosica and other shrubs.

However , Dengkou County is next to Yellow River , underground water level higher than Yanchi

County, and Tamarix Chinensis is deep roots tree, biological soil crusts on their impact can be ignored. Thus causing biological soil crusts thickness increased, the coverage also increased, which is more conducive to the succession of Tamarix Chinensis community, Artemisia ordosica community is likely to decline in the next few years, and retreat from the meadow.

Comparison of the distribution characteristics of the biological soil crusts in two kinds of desertification ecosystems. The effect of factor thickness, biological soil crust thickness under Artemisia ordosica coverage in Mu Us desert bigger than that in Ulan Buh desert. However, biological soil crust thickness under Hedysarum Mongolicum and Hedysarum Scoparium coverage less than that under Tamarix Chinensis coverage, which is related to the site conditions. Yanchi County altitude is above $1500 \mathrm{~m}$, and Dengkou County is only $1050 \mathrm{~m}$, different altitude leads to different annual rainfall. Although Dengkou County is close to Yellow River, the rainfall is the most important factor in the desertification area, the soil surface is mainly influenced by rainfall, and only the deep rooted trees can be less affected by rainfall. The different characteristics of the biological soil crusts also caused the difference distribution characteristics. In Dengkou County, lichen and moss crusts on the surface appear salinization and to explore the reasons found in the study area was originally a flood, but less rainfall for many years caused the water level decline. 


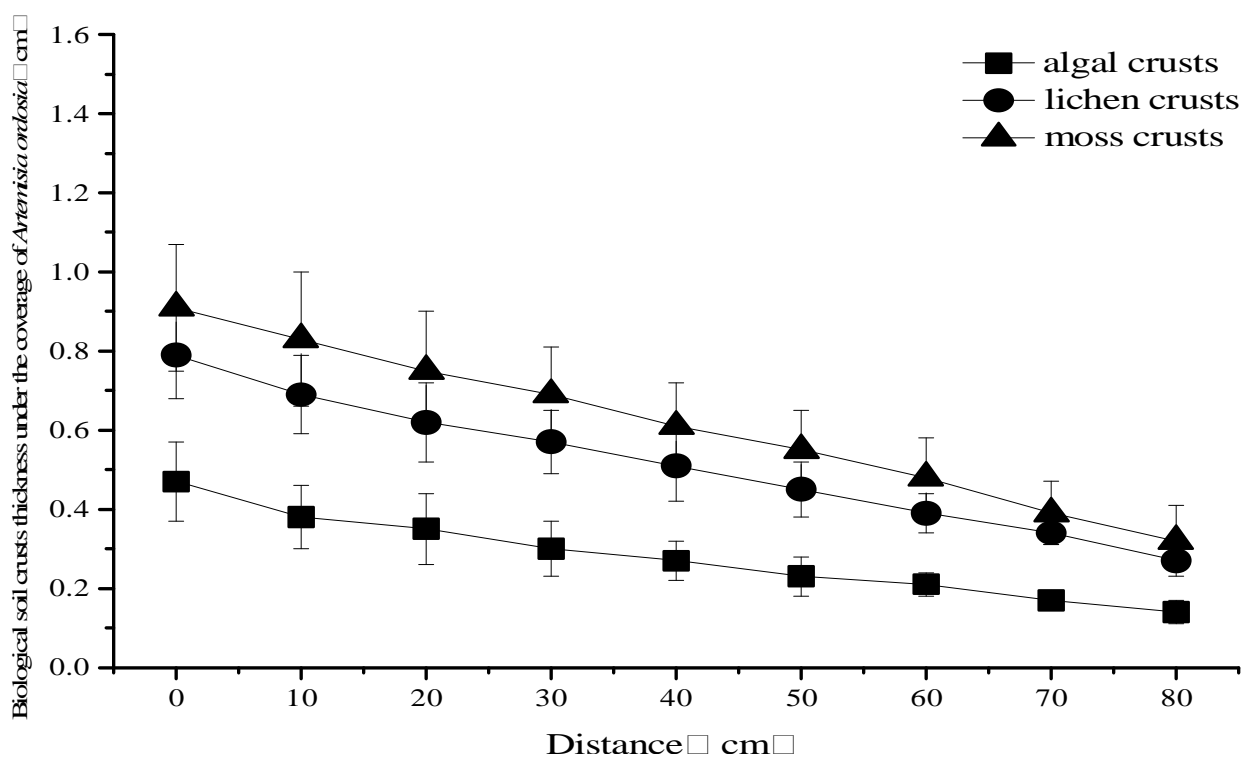

Fig.5 Biological soil crusts thickness under the coverage of Artemisia ordosica in Ulan Buh desert

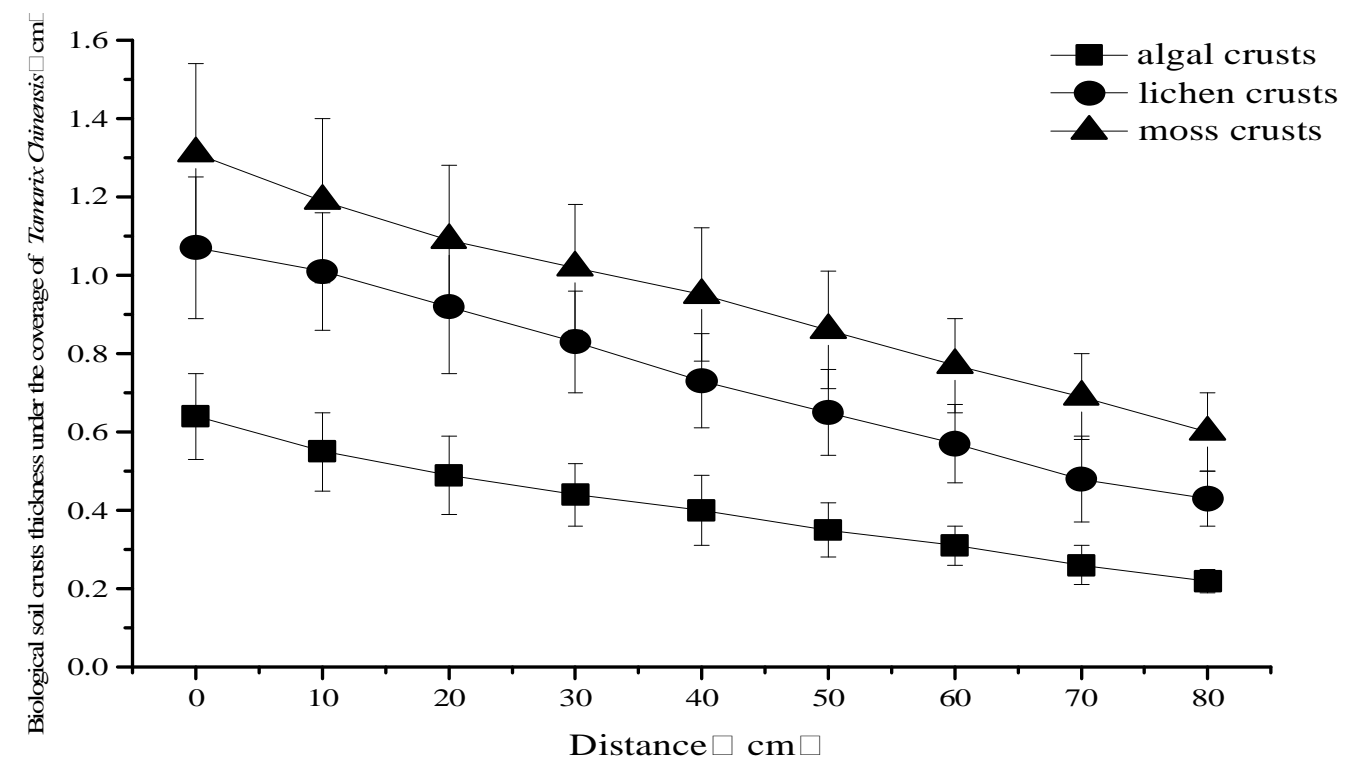

Fig.6 Biological soil crusts thickness under the coverage of Tamarix Chinensis in Ulan Buh desert

\section{Discussion}

The distribution of biological crusts is closely related to the spatial scale $\mathrm{e}^{[17]}$. The spatial scale has a significant effect on the distribution of the biological crusts ${ }^{[18]}$. Temperature and precipitation are the biggest influencing factors ${ }^{[19]}$. Different temperature and rainfall bring different habitats, and the developmental conditions of biological soil crusts show different distribution characteristics. The main factors that control the distribution of biological soil crusts are the altitude, soil conditions, and microclimate ${ }^{[20]}$. Biological soil crusts cover rate and the vegetation cover rate were negative correlation $^{[21]}$. The coverage of biological soil crusts increased, and the utilization rate of water and nutrients in the barrier to the water and nutrients, resulting in the decline of vegetation, so as to affect the vegetation cover gradually reduced. With the increase of vegetation coverage, the distance of the plant root was less, biological soil crusts thickness was greater. The thickness of biological soil crusts is too large, but it is unfavorable to the moisture of the soil, the vegetation can't get enough moisture, so that it can affect the continuous recovery of vegetation, and it is also one of the 
reasons that lead to the decline of the old fixed dunes ${ }^{[10,22]}$ 。

\section{Conclusion}

In advantages plant community of two kinds desertification ecosystem, when the distance of the vegetation root was greater, three types biological soil crusts under the same vegetation coverage was smaller. The average thicknesses of the three types biological soil crusts under the different vegetation cover and the same distance from the root of the vegetation, which are ordered by moss crusts> lichen crusts > algae crusts. Biological soil crusts thickness under Artemisia ordosica coverage in Mu Us desert was greater than that in Ulan Buh desert. Biological soil crust thickness under Hedysarum Mongolicum and Hedysarum Scoparium coverage less than that under Tamarix Chinensis coverage.

\section{Acknowledgements}

This project was funded by the Non-Profit Special Fund of MWR (grant no. 201501045).

\section{References}

[1] H.Y. Fang, Q. G. Cai, H. Chen, et al. Mechanism of formation of physical soil crust in desert soils treated with straw checkerboards. Soil\& Tillage Research, 93(2007)222-230.

[2] Z. H. Duan, H. L. Xiao, X. R. Li, et al. Evolution of soil properties on stabilized sands in the Tengger Desert, China. Geomorphology, 59(2004)237-246.

[3] D. R. Yan, Y. Y. Xue, F. J. Han, et al. Present study on biological soil crusts in abroad deserts. Journal of Inner Mongolia Forestry Science \& Technology, 33(2007)39-44.In Chinese.

[4] B. Xiao, Y. G. Zhao, M. A. Shao. Effects of biological soil crust on soil physicochemical properties in water-wind erosion crisscross region, northern Shaanxi province, China. ACTA Ecollgica Sinica, 27(2007)4642-4670. In Chinese.

[5] Y. P. Liu, L. J. Ci. The evaluating indicator system of grass land desertification in Mu Us sandy land. Jounal of Desert Research, 18(1998) 366-371. In Chinese.

[6] Chen, Y., J. Tarchitzky, J.Brouwer, J. Morin, and A. Banin. Scanning electron microscope observations on soil crust and their formation, Soil Sci., 130(1980)49-55.

[7] Epstain E., and W.J. Grant. Soil crust formation as affected by raindrop impact, p195-201, In L. A., Hadas(de.)Ecological studies, Vol,4, physical aspects of soil water and salts in ecosystems, Spring-Verlay, New York, 1973.

[8] Mcintyer. Soil splash and the formation of surface crust by raindrop impact, Soil Science, 85(1958)261-266.

[9] Onofiok, O., and M. J. Singer. Scanning electron microscope studies of surface crusts formed by simulated rainfall, Soil Sci. Soc. Am. J., 48(1984)1138-1143.

[10] Y. Cui, Y. Z. Lv, B. G. Li. Physico-chemical properties of soil microbiotic crusts on Erdos plateau. Soils, 36(2004)197-202. In Chinese.

[11] Gundlapally S R, Garcia-Pichel F. The community and phylogenetic diversity of biological soil crusts in the Colorado plateau studied by molecular fingerprinting and intensive cultivation $[\mathrm{J}]$. 
Microbial Ecology, 52(2006) 345-357.

[12] J. H. Zhang. Distribution and dynamic of soil moisture in Artemisia ordosica community in $\mathrm{Mu}$ Us sandy land. Chinese Academy of Forestry, Beijing, 2013. In Chinese.

[13] X. L. He, H. L. Shi, Z. B. Bai, C. Y. Liu. Temporal-spatial distribution characteristics of precipitation event frequency and intensity in east of Hexi corridor. Agricultural Research in the Arid Areas, 27(2009)248-259. In Chinese.

[14] Q. Cui, J. R. Gao, M. Y. He, Z. G. Zhao, J. R. Zhang. Effects of Farm land Shelterbelts in Controlling Wind and Sand in Sandy Land of Yanchi. Journal of Ecology and Rural Environment, 25(2009)25-29. In Chinese.

[15] B. Li. Study on the distribution and hydrological characteristics of biological soil crusts in different desertification ecosystem areas. Beijing Forestry University, Beijing, 2015. In Chinese.

[16] Gundlapally S R, Garcia-Pichel F. The community and phylogenetic diversity of biological soil crusts in the Colorado plateau studied by molecular fingerprinting and intensive cultivation. Microbial Ecology, 52(2006)345-357.

[17] D. R. Yan. Study on fertile islands features of biological soil crusts in Kubuqi Desert. Inner Mongolia Agricultural University, Hohhot, 2008. In Chinese.

[18] S. Z. Li, H. L. Xiao, F. Luo, et al. Regulation effect of microbiotic crusts on soil hydrological process in Shapotou vegetated sanddunes. Jounal of Desert Research, 25(2005)228-233. In Chinese.

[19] Roger R W.Soil surface lichens in arid and subarid south-eastern Australia.III.The relationship between distribution and environment. Australia lournal of Botany, 20(1972) 301-316.

[20] Belnap J, Gillette D A. Vulnerability of desert biological soil crusts to wind erosion: the influences of crust development, Siol texture, and disturbance. Journal of Arid Environments, 39(1998) 133-142.

[21] Malam Issa, Trichet J, Defarge C. Morphofogy and mierostructure of microbiotic soil crusts on a tiger bush sequence(Niger,Sahel). Catena, 37(1999)175-196.

[22] J. Liu, K. B. Zhang, L. M. Meng, et al. Effect of Different Measures for Protection and Restoration on the Plant Diversity in Yanchi County. Research of Soil and Water Conservation,17(2010) 181-185. In Chinese. 